\title{
ORDINARY KINDS AND ONTOLOGICAL ANGST. REPLY TO DEMARTINI ${ }^{1}$
}

\author{
MARIO GÓMEZ-TORRENTE \\ https:/ / orcid.org/0000-0002-5957-6544 \\ Instituto de Investigaciones Filosóficas \\ Universidad Nacional Autónoma de México (UNAM) \\ Mexico City \\ Mexico \\ mariogt@unam.mx
}

Article info

CDD: 121.68

Received: 01.10.2020; Accepted: 17.10.2020

https://doi.org/10.1590/0100-6045.2020.V43N4.MT

\section{Keywords}

Numeral Kind Terms

Reference

Ontology

Abstract: Thainá Demartini has criticized my view that ordinary natural kind terms refer to vague non-scientific kinds and defended the more traditional view that they refer to precise kinds discovered by science. In this note I reject Demartini's worries as based on inadequate ontological scruples.

In Roads to Reference I postulate that the referents of ordinary natural kind terms, such as the paradigmatic "water", are typically what I call ordinary kinds, which are kinds or properties that differ fundamentally from the scientific kinds with which those terms are typically associated in

${ }^{1}$ Support from the research project no. PIDPID-107667GB-I00 of the Spanish Ministry of Science and Innovation is gratefully acknowledged. 
being vague along many dimensions along which scientific kinds are precise. Thainá Demartini's (2020) fundamental worry is, I think, that an ontology of ordinary kinds is too lavish: "instead of postulating two distinct ontological kinds, the ordinary and the scientific, why not consider a view... having fewer ontological commitments?)?" Now of course if we don't believe in ordinary kinds, we cannot make them the referents of ordinary natural kind terms. Demartini thus wants to defend the orthodox idea that these terms refer to the scientific kinds they are typically thought to refer to-that "water" refers to $\mathrm{H}_{2} \mathrm{O}$, for example.

But how could this come about, in view of the fact, described and discussed at length in Roads to Reference (see Gómez-Torrente (2019), 171ff.), that an ordinary kind term like "water" appears to have an intuitive determinacy profile different from the profiles of all the scientific kinds with which "water" could be relevantly associated (including $\mathrm{H}_{2} \mathrm{O}$ )? Demartini's idea is that an ordinary kind term is context-sensitive in such a way that some aspect of the context, when it is present, makes the term refer to a scientifically precise kind, while, when it is not present, its absence makes the term "seek" a reference with the vague determinacy profile of what I call ordinary kinds; but since such ordinary kinds don't exist, when that hypothetical feature of context is absent, the ordinary kind term presumably ends up failing to refer.

The idea strikes me as indefensible at first sight, not least because I can't see any linguistic evidence that could back up the hypothesis of such contextual sensitivity-and Demartini does not provide any such evidence, as far as I can tell. Nevertheless, I suppose that Demartini's idea might still be implemented if we understand it somewhat differently (and she may have understood it in this different way herself), as consisting in something that might not 
strike us as so unlikely: it is conceivable that "water" is ambiguous (or polysemous) in such a way that under one of its acceptations the term refers to a scientifically precise kind, while, under another, the term (or the conventions that govern it under that acceptation) "seeks" a reference with the vague determinacy profile of what I call ordinary kinds; but since such ordinary kinds don't exist, when that acceptation is in play the ordinary kind term presumably ends up failing to refer. Even if the idea thus understood is still unlikely at first sight, as an ambiguity thesis it is linguistically less demanding than the contextual sensitivity thesis, and not so implausible. After all, we know that it is a fact that "water", like the vast majority of words in our natural languages, is ambiguous or polysemous (as a quick look at Wiktionary will confirm), and that we competent speakers are not infallible when it comes to distinguishing clearly between the acceptations of the words we competently use. Who is to say that in this case we have not been missing a philosophically relevant distinction between two acceptations of "water"? Even among philosophers used to reflecting on their linguistic intuitions, a relevant distinction between acceptations may have gone unnoticed. Recall also that, in the very case of "water", Putnam postulated an ambiguity, between the "natural kind" acceptation that appears to be predominant in philosophical discussions at least since the Kripke-Putnam orthodoxy concerning natural kind terms emerged, and a descriptive acceptation, on which "water" would be essentially synonymous with something like "transparent, odorless, tasteless liquid filling rivers, lakes and oceans" (see Putnam (1975), 239).

Even if an ambiguity reconstruction of Demartini's idea is not entirely implausible, it's hard to see that it could be correct. Perhaps the least implausible feature of the idea is that under one of its acceptations "water" refers to a 
scientifically precise kind, for it is not implausible to think that by now "water" may simply have acquired a consolidated use as synonymous with " $\mathrm{H}_{2} \mathrm{O}$ " in some scientific discussions (and perhaps even in some nonscientific discussions which nevertheless use the ordinary term in some way that is deferential with respect to the predominant scientific (and philosophical) use). But if such acceptation exists by now, its existence can nevertheless not be the basis for thinking that "water" is ambiguous in the way Demartini needs. For she surely needs it to be the case that at least a vast majority of uses of "water" come out as having a conventional referent, but the kind of contemporary use in which "water" is just synonymous with " $\mathrm{H}_{2} \mathrm{O}$ " cannot ground a fact of that kind. For one thing, the immense majority of uses of "water" simply preceded even the appearance of the concept of being $\mathrm{H}_{2} \mathrm{O}$, and the vast majority of contemporary uses are likewise uses in the mouth of speakers who haven't heard of such a thing as $\mathrm{H}_{2} \mathrm{O}$.

Demartini needs two acceptations of "water" that somehow work together in such a way that under the first "water" refers to $\mathrm{H}_{2} \mathrm{O}$ while under the second it fails to refer. I suppose that thinking up some story on which "water" (in one acceptation) failed to refer-on account of its vagueness, for example-would not be that hard. But the problem will still be how to make room for the requirement that "water" (in the other acceptation) refers precisely to $\mathrm{H}_{2} \mathrm{O}$ (or to any other precise scientific kind). For recall that "water" is the ordinary term, and, ambiguous or not, philosophers reflecting on the idea of water have failed to find in it conceptual associations with the complexity required in order to establish a way in which $\mathrm{H}_{2} \mathrm{O}$, as opposed to $\mathrm{P}_{2} \mathrm{O}$, or to the substance consisting of $3 / 4$ orthowater and $1 / 4$ parawater, might become fixed as the referent of (the relevant acceptation of) "water". Even if 
the search for the right conceptual associations has so far proceeded under a tacit assumption of univocity or monosemy, presumably the search has not been affected by the assumption - and it has failed to find the associations that might justify the conclusion Demartini needs. In the absence of novel suggestions on her part about how such associations might be located, surely the onus of proof falls on the shoulders of the proponents of the ambiguity view; and univocity views such as the account in Roads to Reference come out unharmed.

The root of Demartini's worries is, as in so many other cases in contemporary philosophy, a species of ontological anguish. Regardless of how justified this sort of anguish may be in other areas of philosophy (my personal view is that it is more often unjustified than not), it may be important to insist that in the case of ordinary kinds the anguish seems hardly justified. Ordinary kinds are simply vague properties, like the vast majority of properties out there, and, unless we want to condemn all properties whatsoever to the limbo of inexistence, ordinary kinds are thus nothing out of the ordinary (if I'm allowed the pun). Denying their existence is denying the existence of something perfectly commonplace and familiar, and accepting it should not cause us undue anguish, especially given that it can provide us with good tools for making sense of the referential status of natural kind terms as well as of other linguistic expressions. ${ }^{2}$

${ }^{2}$ A worry that is evidently also present in Demartini (especially in her discussion of generics and generic claims involving ordinary natural kind terms) is that it may only be with precise scientific properties as referents that ordinary kind terms could be seen to play their natural function of helping us to generalize inductively from properties of known cases to properties of new cases-it would be only in view of the existence of the scientific refterents or ordinary kind terms that we could see how such 


\section{REFERENCES}

Demartini, T. (2020), "Natural Kinds and our Semantic Intuitions Along the Road", Manuscrito, this issue.

Gómez-Torrente, M. (2019), Roads to Reference. An Essay on Reference Fixing in Natural Language, Oxford University Press, Oxford.

Putnam, H. (1975), “The Meaning of 'Meaning' ", in K. Gunderson (ed.), Minnesota Studies in the Philosophy of Science, Volume 7: Language, Mind and Knowledge, University of Minnesota Press, Minneapolis, 131-93. Reprinted in Putnam, Philosophical Papers, Volume 2: Mind, Language and Reality, Cambridge University Press, Cambridge, 1975, 215-71. Reference to the reprint.

\section{$(c c)$ EY}

generalizations could have always worked in the first place. But a correct view of this phenomenon does not require that the referents of ordinary kind terms are scientific kinds, but merely that scientific kinds be appropriately connected with the vague referents of ordinary kind terms; for some indications on what the appropriate connection is, see Gómez-Torrente (2019), $180 \mathrm{ff}$. 